\title{
Considerations for Selection and Use of Ornamental Grasses ${ }^{1}$
}

Mack Thetford ${ }^{2}$

\section{Introduction}

Ornamental grasses are one of the most interesting and exciting groups of plants to be introduced to the landscape market in the past few years. The availability of a large number of species and cultivars makes these plants very versatile with many potential uses in the landscape. The diversity of grasses has also led to many questions concerning the proper selection and use of ornamental grasses. The following information should assist the first time gardener as well as the experienced landscaper in the selection and use of ornamental grasses in Florida.

\section{Types of Ornamental Grasses}

The term "ornamental grass" is one of those catch-all phrases used to describe not only true grasses but related "grasslike" plants as well. True grasses are in the plant family, Poaceae, while the grasslikes generally fall into one of two plant families: the rushes, which represent the plant family Juncaceae, or the sedges, which represent the Cyperaceae family. All three plant families contain plants adapted to a wide variety of environments and planting conditions. Within each of these plant families one will find individual species adapted to a wide variety of landscape sites (ie wet or dry, sun or shade, hot or cold climates, or any combination thereof). Growth habits range from low ground covers to intermediate shrub-like plants to very tall hedge-like plants. Ornamental grasses are very dynamic; the size, shape, texture and color of grass will change with every season.

\section{Characteristics to Consider}

When deciding how to use ornamental grasses in the landscape first consider the plant characteristics outlined in Table 1.

The first characteristic to consider is if the plant is an annual or perennial. A perennial grass will live for many years while an annual grass will only last one season and will die after flowering or it may be killed when exposed to freezing temperatures. Other characteristics to consider when making your grass selections include knowing if the foliage is winter hardy (evergreen) or not (deciduous) growth form, mature size, foliage color, and time of flowering. Much of this information should be available from catalog descriptions.

1. This document is ENH 976, one of a series of the Environmental Horticulture Department, Florida Cooperative Extension Service, Institute of Food and Agricultural Sciences, University of Florida. Original publication date April 2004, revised January 2006. Please visit the EDIS web site at http://edis.ifas.ufl.edu. For more information, contact your County Cooperative Extension Service office.

2. Mack Thetford, associate professor; Environmental Horticulture Department, Cooperative Extension Service, Institute of Food and Agricultural Sciences, University of Florida, 5988 Highway 90, Bldg. 4900, Milton, FL 32583.

The Institute of Food and Agricultural Sciences (IFAS) is an Equal Opportunity Institution authorized to provide research, educational information and other services only to individuals and institutions that function with non-discrimination with respect to race, creed, color, religion, age, disability, sex, sexual orientation, marital status, national origin, political opinions or affiliations. U.S. Department of Agriculture, Cooperative Extension Service, University of Florida, IFAS, Florida A. \& M. University Cooperative Extension Program, and Boards of County Commissioners Cooperating. Larry Arrington, Dean 


\section{Winter Characteristics}

The winter appearance of an ornamental grass will differ with the winter hardiness of the foliage. In terms of landscape design, evergreen grasses function similarly to evergreen shrubs while deciduous grasses may function similarly to herbaceous perennials. For many gardeners, the winter character of deciduous ornamental grasses is much more important than the spring and summer foliage or flowers. The mature flowers of grasses may remain intact through the winter or they may shatter. Regardless, these dead, dry features add tremendous interest to the winter garden when contrasted with evergreen plants or structures such as walls or fences. The dried foliage of deciduous grasses creates sound as it expands and contracts in response to changes in temperature or moisture while interaction with wind creates movement in the garden. For these reasons pruning of the dead foliage and inflorescences is not recommended until growth resumes in the early spring.

\section{Invasive Potential}

The invasive potential of ornamental grasses has been of concern for a long time. In Florida the issue is broader because many of our native areas are fire-dependent ecosystems dominated by grass species. The escape of a non-native grasses into these areas might displace native species. Also non-native grasses in native ecosystems may alter natural fire regimes. The temperature at which a non-native grass burns, or the ability of the non-native grass to carry fire across an ecosystem, may be different from that of native species.

There is already some concern in other areas of the U.S. with regard to grass species listed in this article. Pampas Grass (Cortaderia selloana), although not considered a problem species in Florida, is considered a pest in California. Similarly, volunteer seedlings of Japanese Silvergrass (Miscanthus) have been reported in several northern states. Japanese Blood Grass (Imperata cylidrica) has been banned in the state of Florida and is among the world's worst weeds. What this information is meant to show is that a grass can be invasive in one climate and perfectly acceptable in another climate or region. What this means to the Florida gardener is the information derived from local growers and regional experts will be important and the most desirable selections for their region may also include regionally native grasses. Gardeners concerned with the invasiveness of ornamental grasses should contact their local County Extension office for the latest available information on plants considered invasive in Florida.

\section{Availability}

Since ornamental grasses are a relatively new group of plants for Florida landscapes, many local garden centers may not have very large selections. Don't be bashful: if you don't find what you're looking for, ask your local garden center to locate and stock these plants. For those selections you do find locally, be prepared to see plants that may not be as attractive as those pictured in catalogs and magazines. Many grasses, especially those that quickly reach heights above 3 to 4 feet, may require pruning during the production cycle to prevent the wind from toppling the plants. Tall plants are also difficult to ship from the grower/producer to the garden center so this may make some of the larger, taller selections a bit more difficult to locate. Remember, the way a grass looks in a pot at the garden center may not reflect the ultimate appearance or size it will have once established in the garden.

\section{Growth Form and Mature Size}

The growth form and mature size will influence how an ornamental grass should be used in the landscape. Ornamental grasses can be characterized as either clump forming or creeping. Clump forming grasses, also called bunch grass, grow in compact tufts, the width at the base slowly increasing over time. Mountain oats (Chasmanthium latifolium is an example of a clump forming grass (Figures 1 and 2). Creeping grasses are also called running or spreading grasses and spread by above-ground stems called stolons or underground stems called rhizomes. 'Feesey's Form' ribbon grass (Phalaris arundinaceae 'Feesey's Form') is an example of a creeping grass (Figures 3 and 4). Grasses that spread by stolons or rhizomes form roots along these stems, making many of them difficult to maintain within a confined area. Be sure to select the growth form best suited to your garden site. 


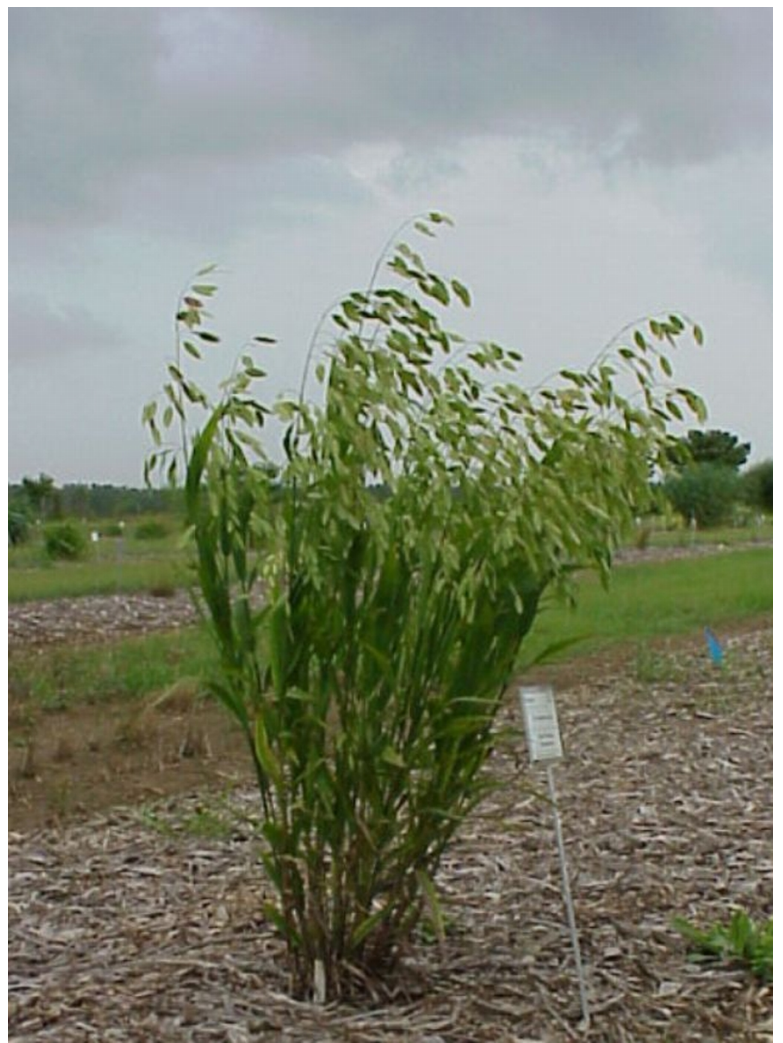

Figure 1. Mountain oats.

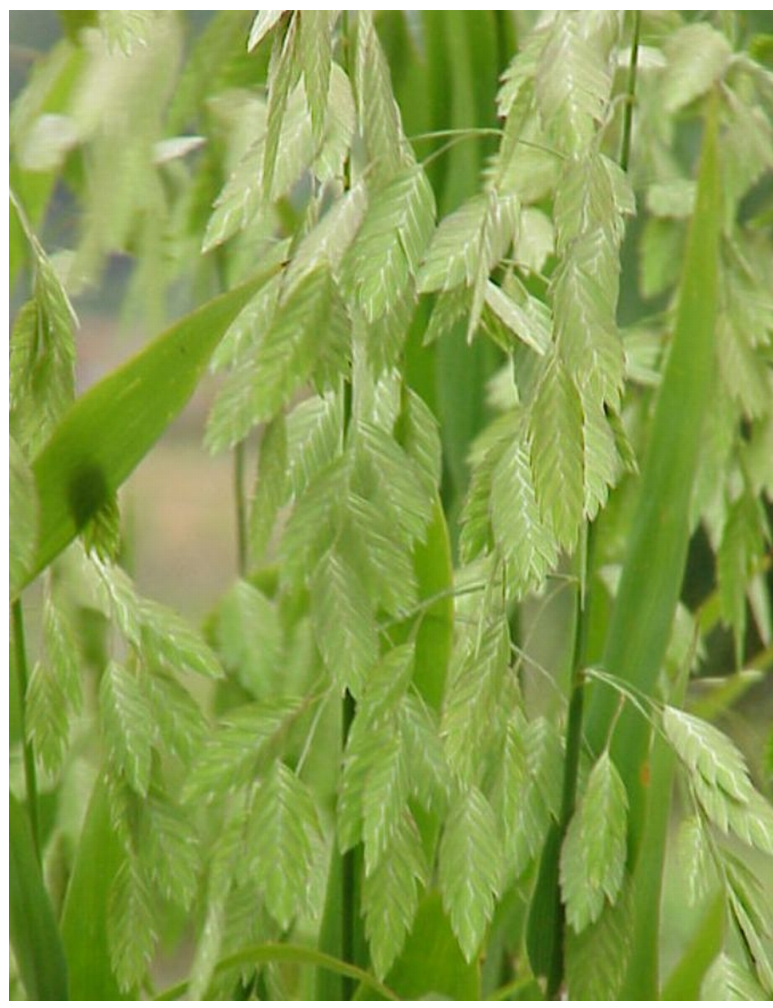

Figure 2. Mountain oats seedheads.

The mature size of a grass should be used as a guide to determine where it should be placed in the garden. We will consider three arbitrary size

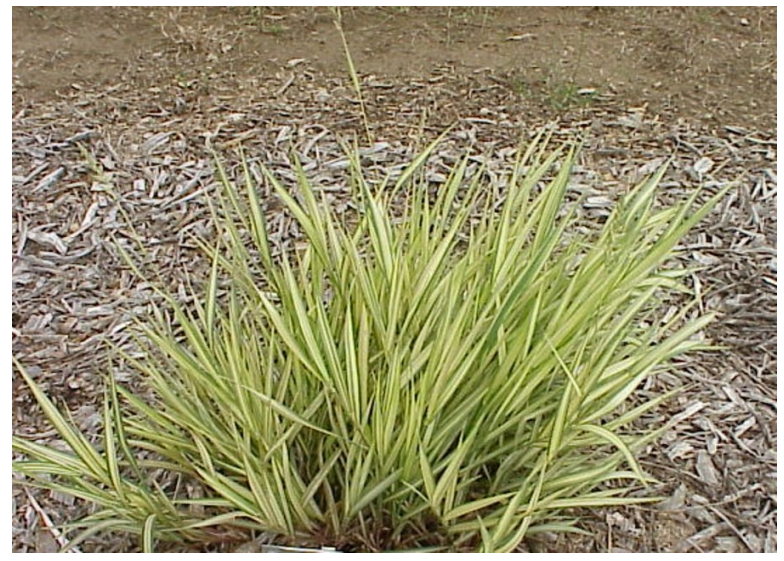

Figure 3. Ribbon grass.

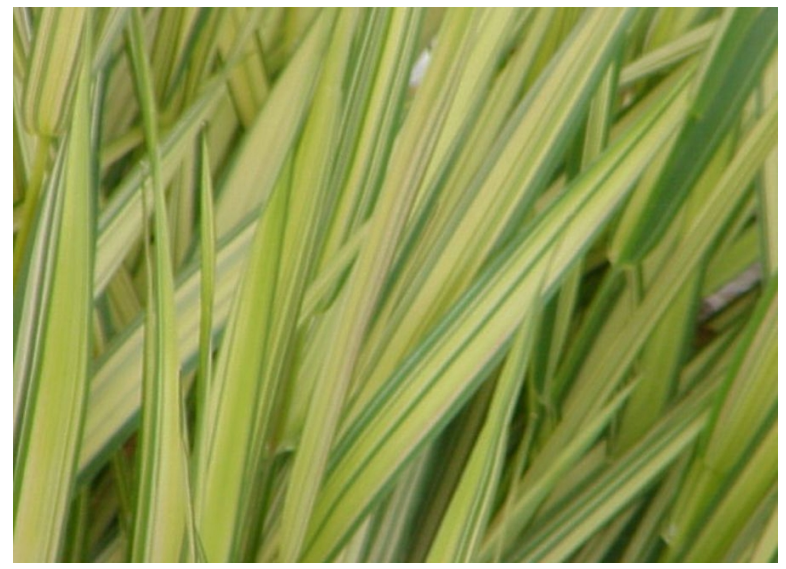

Figure 4. Ribbon grass foliage.

groupings, short, medium and tall, to provide examples of how grasses can be used. The distinctions between these groups may vary according to gardeners' perceptions of height and growing conditions. In particular, water and nutrient availability will influence plant size. An important consideration to remember is that although the mature size of the grass is important in selection and placement in the garden, a majority of our grasses are dynamic and do not remain the same height throughout the growing season because of pruning of deciduous foliage or flowering characteristics.

\section{Use of Ornamental Grasses}

\section{Short Grasses}

Short grasses can be used in small groups for a massing effect or in large groups as a living ground cover. Small clumping grasses such as dwarf selections of silver grass or fountain grass (Figure 5) provide an excellent border between plant beds and walkways while small spreading grasses such as 
ribbon grass make an excellent ground cover. These plants also make good accent plants among other short annual or perennial species. The weeping effect of grass leaves over the edges of pots and planters softens and hides container edges, so don't forget to consider short grasses as candidates for mixed planters or individual pots.

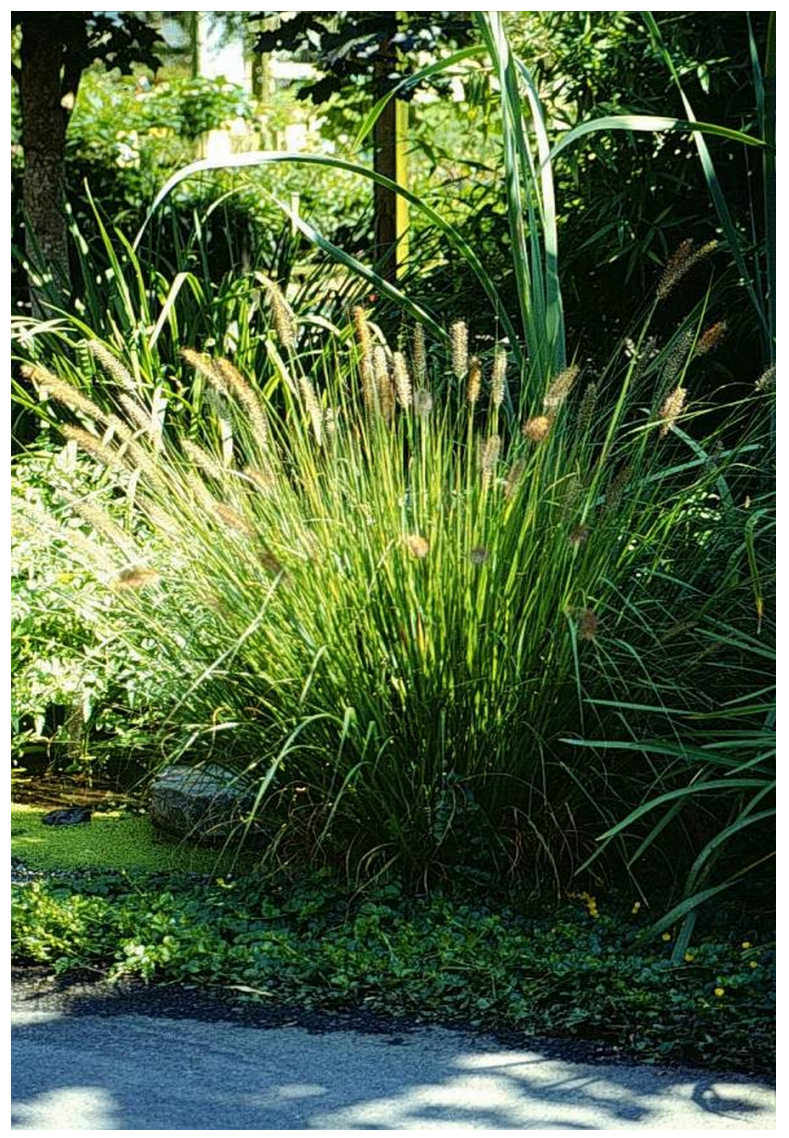

Figure 5. 'Hameln' fountain grass.

\section{Medium Grasses}

Medium grasses can also be used as accents among shrubs or herbaceous perennials or annuals. The shrubs serve as the permanent vertical elements of the planting design while the height and shape of the grasses will vary with the season. Medium grasses may also be used to define areas within the landscape that do not require a solid screen. An example would be a hedge of zebra grass used as a wind block near a seating area. In the early spring the plants are only a few inches tall and will not effect the spring and summer breezes. As the plants grow to a height of 4 to 5 feet by fall they provide fall and winter wind protection. Other medium grass selections include muhly grass (Figure 6), which may be used in mass plantings or as ground cover or leather leaf sedge, which can be used as an accent plant within plantings of annuals such as wax begonia.

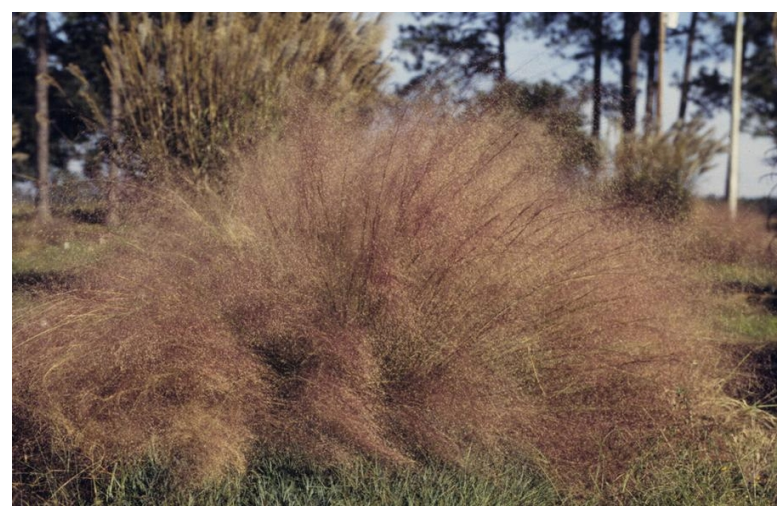

Figure 6. Muhly grass.

\section{Tall Grasses}

Tall grasses provide a strong vertical element in the garden. Tall grasses with arching leaf tips can also be used to help soften the harsh vertical lines of structures. Evergreen grasses such as pampas grass can be used to divide the garden into sections or as a transitional plant between a tall hedge and shorter shrubs or perennials. Other tall grasses such as many of the Japanese silver grasses (Figure 7) also work well in the mixed shrub and perennial borders. Early in the season these plants do not dominate this type of planting because of their short stature. As the season progresses into the hot summer, they grow and become a more dominant element. During the fall months, when little else is flowering or drawing attention, a grass like 'Burgundy Giant' fountain grass with its burgundy foliage and rose purple flowers will take center stage.

\section{Evergreen vs. Deciduous}

Once growth form and size have been considered, determine if the grass is deciduous or evergreen. This may not be an easy process since many grasses behave differently in different climates. Grasses are classified as warm season or cool season. Warm season grasses are active in the warmer months and tend to go dormant in the winter. Dormant warm season grasses may remain green or the foliage may freeze, die and remain intact until pruned. Cool season grasses are active in the cooler months and are more likely to remain evergreen during the winter. A hard freeze may effect even "evergreen" grasses by 


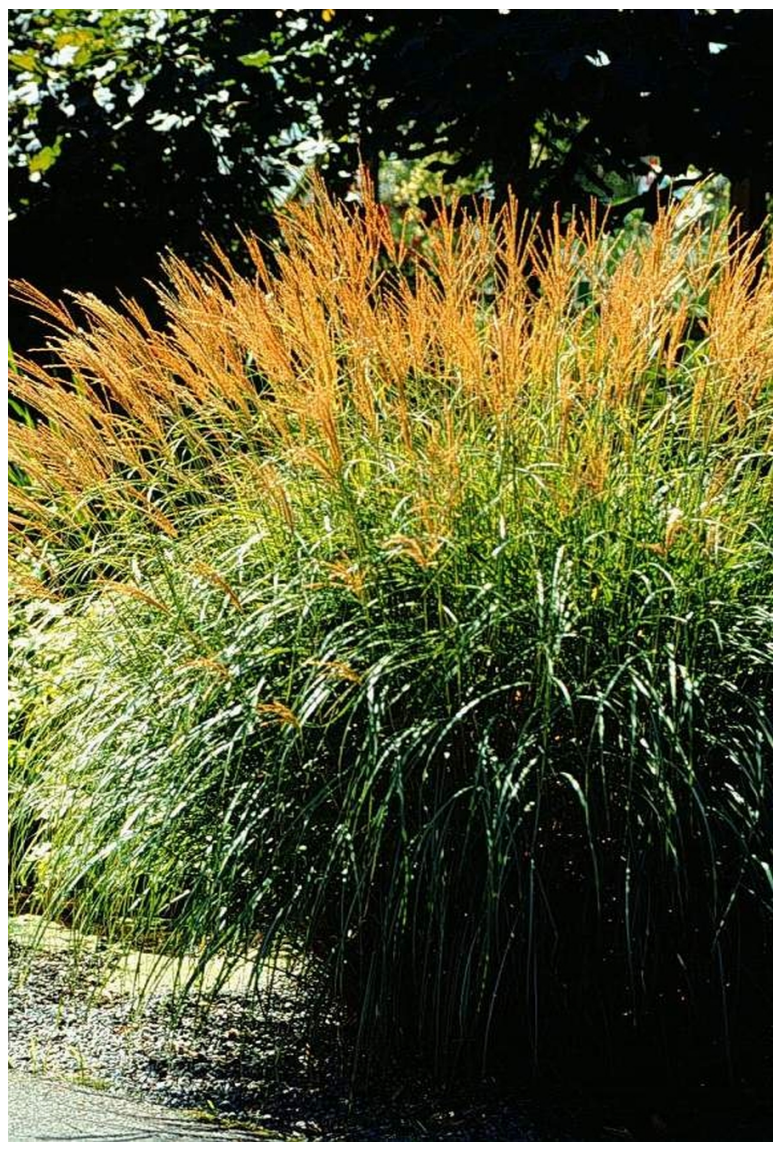

Figure 7. 'Arabesque' silver grass.

damaging the foliage but when warmer conditions return new foliage will usually quickly regrow. Grasses for which the foliage dies in the winter months and remain dormant until the weather warms in the spring are considered deciduous.

\section{Managing Ornamental Grasses in the Landscape}

Ornamental grasses, once established, are relatively easy to manage in the landscape because of their minimal fertility, irrigation, and pruning needs. Maintenance considerations may differ depending on local rainfall patterns, native soil texture and nutrient holding capacity of the planting site.

\section{Watering}

Irrigation may not be necessary for ornamental grasses once they are established in the landscape. In many areas of Florida rainfall is sufficient for most ornamental grasses, particularly those native to the state. After planting, grasses should be watered frequently like a containerized ornamental with the irrigation applied directly to the root ball. After several weeks, the roots of the grass plant should extend beyond the root ball into the surrounding soil. At this point the plant will normally require irrigation only during extremely dry periods. Most grasses should be irrigated with a drip type irrigation system, which will keep the foliage and flowers dry and reduce the potential for leaf diseases.

\section{Fertilizing}

Grasses should obtain sufficient nutrients from the soil if the basic soil fertility recommendations from a soil test are followed. A minimal nitrogen application of $1 \mathrm{lb}$. of $\mathrm{N} / 1000 \mathrm{ft}^{2}$ per year is more than sufficient to meet the nitrogen requirements of most grasses. Beyond these basic recommendations, no additional application of fertilizer nutrients should be necessary to promote growth of healthy foliage or flowering. In fact, excessive application of fertilizer nutrients will result in weak, floppy growth of foliage and weak flowering stems that will not stand up to even mild winds. Timing of fertilizer applications should correspond to periods preceding rapid foliar growth of the plants.

\section{Pruning}

Pruning of ornamental grasses should be done in late winter or early spring, just prior to new shoot growth. Many of the ornamental grasses have spectacular winter characteristics that should be preserved through the winter months. In north and central Florida, gardeners may target the months of February and March as appropriate times to prune ornamental grasses. South Florida gardeners may wish to cut back or trim ornamental grasses in January or February prior to new growth.

For deciduous grasses, such as Miscanthus, the old foliage may be completely removed within inches of the soil. For evergreen grasses, such as muhly grass, the ragged, dead tips of leaves can be removed to neaten the appearance of the plant. Many evergreen grasses recover quickly from a heavier pruning. Old flower stalks and seed heads may be removed any time they no longer have a neat appearance. 


\section{Dividing}

Propagation of ornamental grasses is relatively easy and can be done at the time of pruning.

Clumping grasses may be dug, divided into several pieces, and replanted. Rapid regrowth will immediately follow. Divisions of creeping grasses may be done also at this time and planted in a container or new location. Division of ornamental grasses is not a requirement for sustained landscape performance but many Pennisetum, Miscanthus, and Panicum may exhibit less vigor as they become older. Many times this is a result of the buildup of the dead aboveground parts accumulating over time. Simple division and replanting is an easy way to rejuvenate these older plants. Named cultivars of ornamental grasses should only be propagated by division because seedlings from these plants may express the broader characteristics of the species rather than the specific desirable characteristics of the named cultivar. Grasses can be easily started by sowing seeds in flats or pots in early spring in an area with bright light. Seedling growth is usually rapid and the seedlings may be transplanted directly to containers or the garden. 
Table 1. Characteristics to consider when choosing grasses for your landscape.

\begin{tabular}{||l|l||}
\hline \hline 1. & Annual or perennial \\
\hline 2. & Evergreen or deciduous \\
\hline 3. & Warm season or cool season \\
\hline 4. & Growth form \\
\hline & - Clump forming or creeping (spreading by stolons or rhizomes) \\
\hline & - Mature shape and height \\
\hline 5. & Foliage color \\
\hline 6. & Time of flowering \\
\hline 7. & Winter characteristics \\
\hline 8. & Invasive potential \\
\hline \hline
\end{tabular}




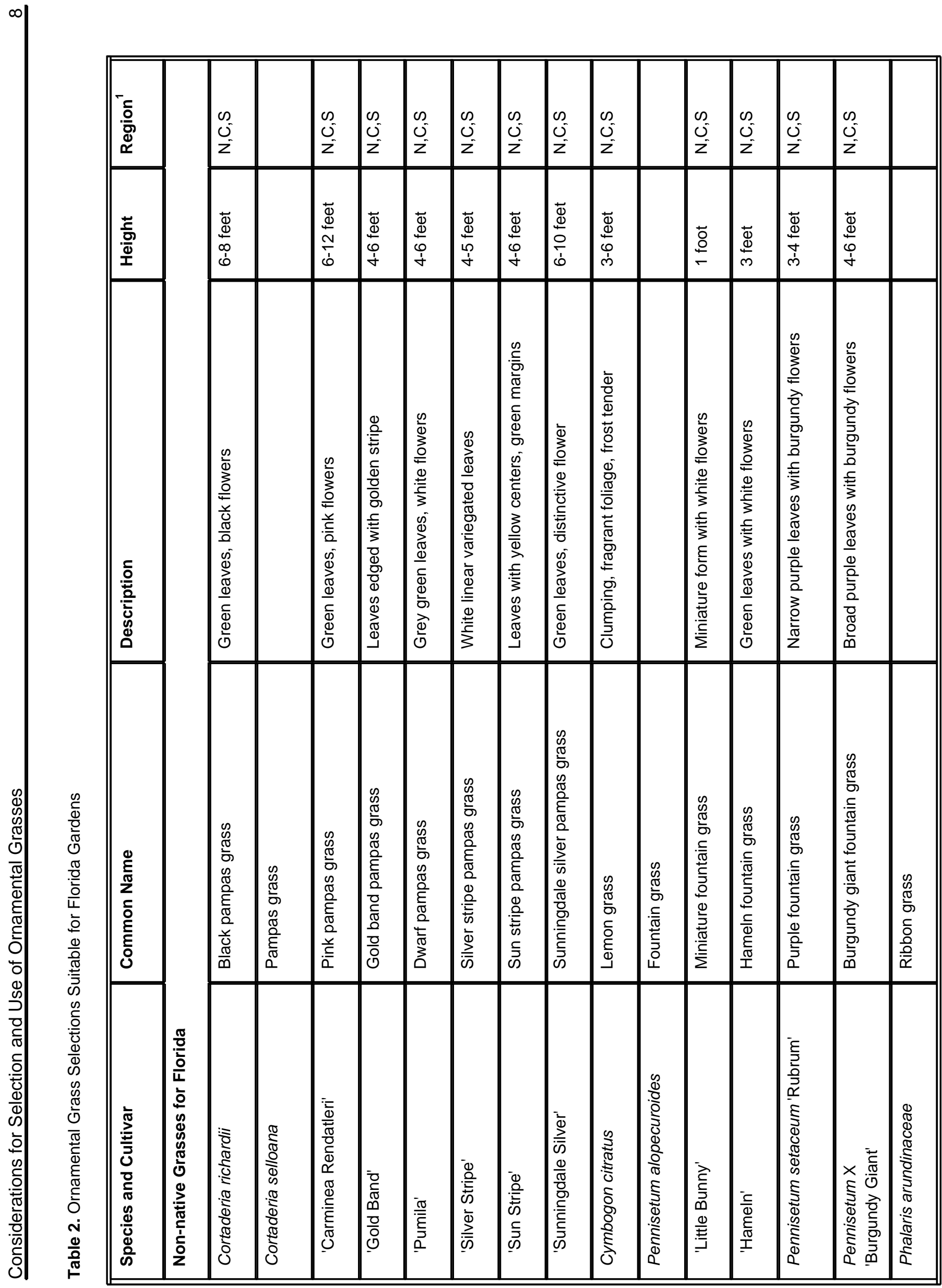




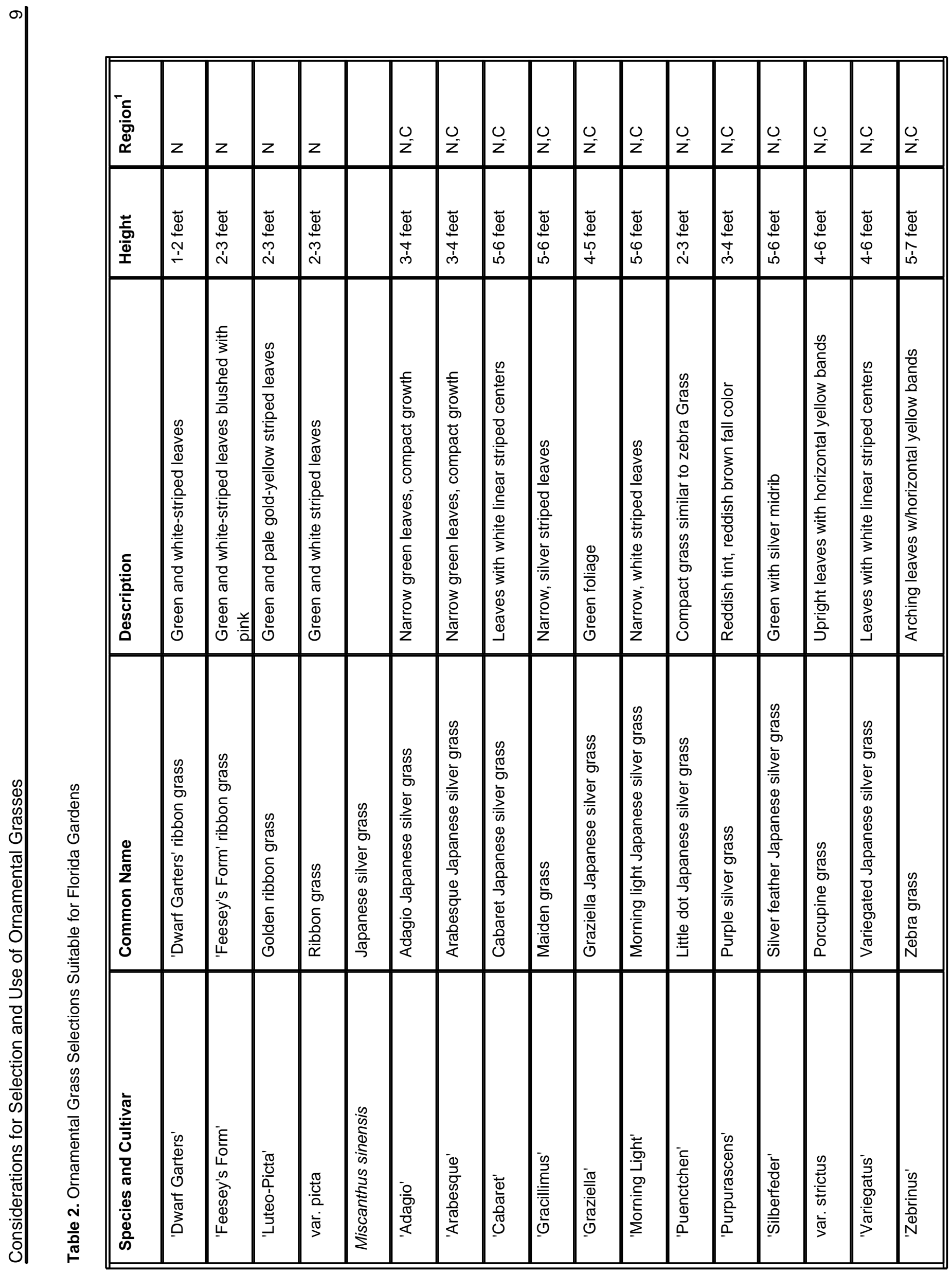




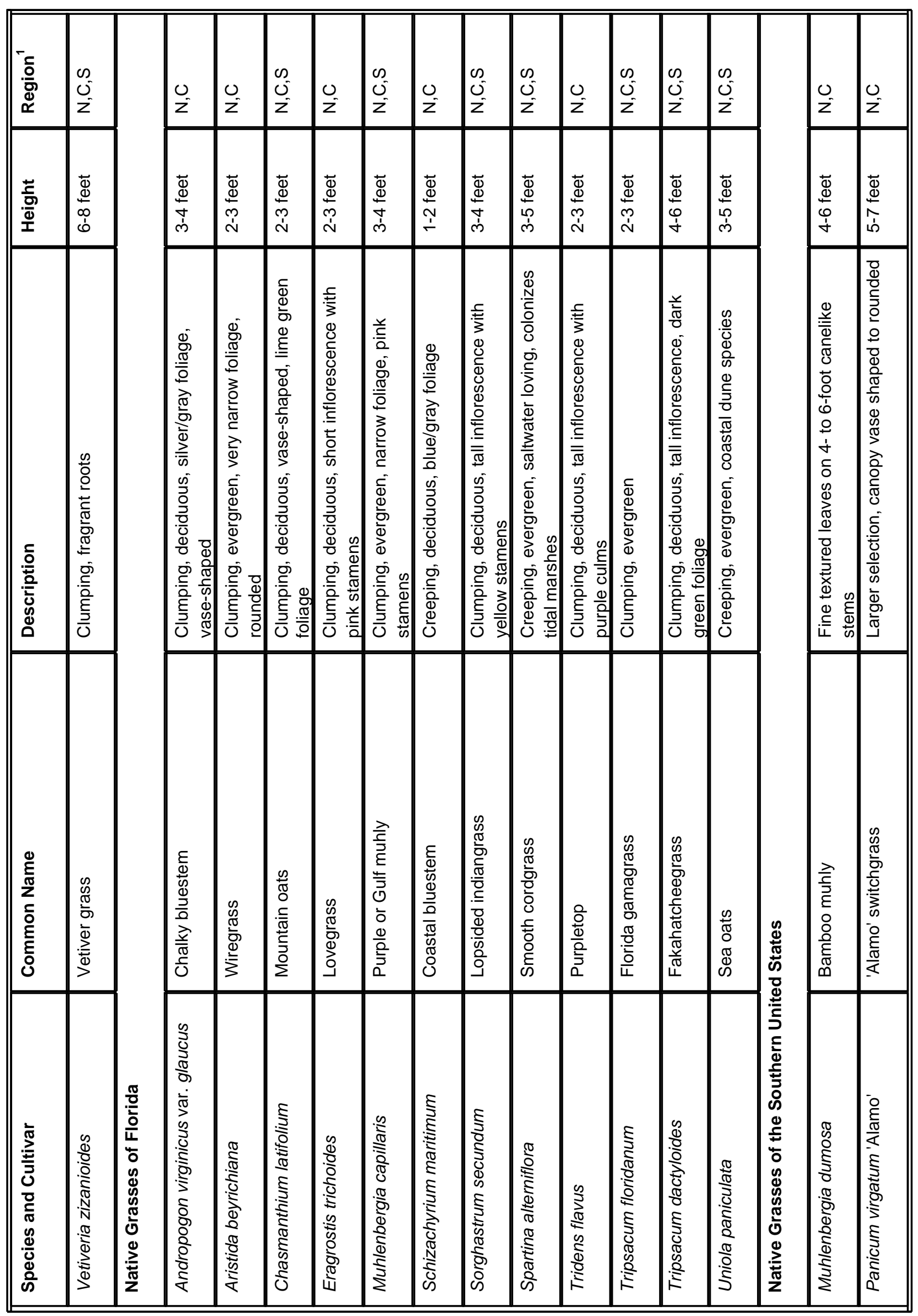




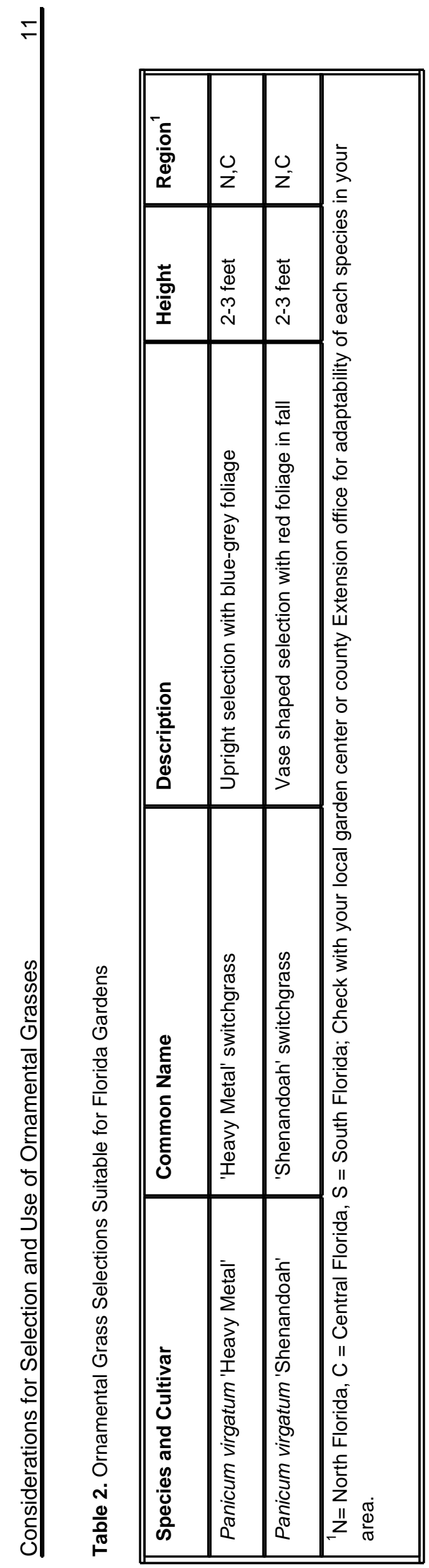

